\title{
Core-Shell Structure of Organic Crystalline Nanoparticles Determined by Relayed Dynamic Nuclear Polarization NMR
}

Pinon, Arthur C.; Skantze, Urban; Viger-Gravel, Jasmine; Schantz, Staffan; Emsley, Lyndon

Published in:

Journal of Physical Chemistry A

Link to article, DOI:

10.1021/acs.jpca.8b08630

Publication date:

2018

Document Version

Peer reviewed version

Link back to DTU Orbit

Citation (APA):

Pinon, A. C., Skantze, U., Viger-Gravel, J., Schantz, S., \& Emsley, L. (2018). Core-Shell Structure of Organic Crystalline Nanoparticles Determined by Relayed Dynamic Nuclear Polarization NMR. Journal of Physical Chemistry A, 122(44), 8802-8807. https://doi.org/10.1021/acs.jpca.8b08630

\section{General rights}

Copyright and moral rights for the publications made accessible in the public portal are retained by the authors and/or other copyright owners and it is a condition of accessing publications that users recognise and abide by the legal requirements associated with these rights.

- Users may download and print one copy of any publication from the public portal for the purpose of private study or research.

- You may not further distribute the material or use it for any profit-making activity or commercial gain

- You may freely distribute the URL identifying the publication in the public portal 


\title{
Core-Shell Structure of Organic Crystalline Nanoparticles Determined by Relayed Dynamic Nuclear Polarization NMR
}

\author{
Arthur C. Pinon, ${ }^{1}$ Urban Skantze, ${ }^{2}$ Jasmine Viger-Gravel, ${ }^{1}$ Staffan Schantz, ${ }^{3}$ and Lyndon Emsley. ${ }^{1}$ \\ ${ }^{1}$ Institut des Sciences et Ingénierie Chimiques, Ecole Polytechnique Fédérale de Lausanne (EPFL), CH-1015 Lausanne, Swit- \\ zerland. \\ ${ }^{2}$ Pharmaceutical Sciences, IMED Biotech Unit, AstraZeneca, Gothenburg, Sweden. \\ ${ }^{3}$ Pharmaceutical Technology \& Development, AstraZeneca, Gothenburg, Sweden.
}

ABSTRACT: The structure of crystalline nanoparticles (CNPs) is determined using dynamic nuclear polarization (DNP) enhanced NMR spectroscopy experiments. The CNPs are composed of a crystalline core containing an active pharmaceutical ingredient (compound P), coated with a layer of PEG (DSPE-PEG 5000) located at the crystal surface, in a $\mathrm{D}_{2} \mathrm{O}$ suspension. Relayed DNP experiments are performed to study ${ }^{1} \mathrm{H}-{ }^{1} \mathrm{H}$ spin diffusion and to determine the size of the crystalline core as well as the thickness of the PEG overlayer. This is achieved through selective doping to create a heterogeneous system in which the $\mathrm{D}_{2} \mathrm{O}$ contains glycerol and organic radicals, which act as polarization sources, and the CNPs are exempt of radical molecules. We observe features that are characteristic of a core-shell system: high and constant DNP enhancement for components located in the surrounding radical solution, short buildup times for the PEG layer, and longer build-up times and time dependent enhancements for compound P. By comparing numerical simulations and experimental data, we propose a structural model for the CNPs with a core-shell organization and a high affinity between the radical and the PEG molecules.

\section{Introduction}

There is great interest in improving drug-delivery systems to provide controlled and targeted release of drug molecules, improved dissolution rates of poorly soluble drugs, or drug delivery across membranes. The number of poorly soluble drugs generated by synthesis is increasing, as are also the challenges for preclinical formulators dealing with this category of compounds. Considerable resources are directed towards attempts to enhance drug solubility and dissolution using conventional formulation systems based on cosolvents, lipids, complex formation and micronization. ${ }^{1-3}$ In spite of these efforts, bioavailability is still an issue and alternative ideas are required to solve solubility related problems. The use of nanocrystals is one of the most important strategies to enhance bioavailability of a poorly water-soluble compounds. ${ }^{4}$ In particular, crystalline drug nanoparticles (CNPs) have the potential to address solubility related problems. ${ }^{5}$ CNPs are defined as colloidal dispersions of crystalline nanoparticles, in which the drug nanoparticles are usually poorly soluble in water. ${ }^{6,7}$ The problem of insolubility can be compensated for by small particle size, usually below $300 \mathrm{~nm}$, in order to enable intravenous drug delivery. The high size-to-surface area ratio enables a faster dissolution rate as compared to larger crystals. Another advantage of CNPs is that the drug content is much higher than in the case of liposomes or micellar systems. Finally, we note that CNPs do not usually involve any problematic additives, and so are often less toxic or less likely to lead to undesirable effects than other formulations. ${ }^{7}$

CNPs are constituted of three main components. First, the dispersion is a water-based solution. The active pharmaceutical ingredient (here compound P, Figure 1a) is present as nanometer size crystalline particles. These CNPs are then coated with a surfactant, for example a DSPE-PEG polymer, which stabilizes the particles and enables reduced sizes in the preparation process of the nanoparticles. Usually, less than $1 \%$ $(\mathrm{w} / \mathrm{w})$ of polymer is needed to provide good stabilization of the particles. Moreover, the DSPE-PEG layers prevent aggregation of the particles in the blood, and make them less prone to uptake by the liver, which can lead to a longer circulation times. ${ }^{8,9}$ Consequently, the choice of the stabilizer plays a crucial role in the stability and dynamics of the CNPs. ${ }^{10-12}$ The properties and thickness of the stabilizing layer are thus key in the conception of such formulations. However, methods to study the structure of these layers are scarce.

In order to measure domain sizes today several techniques are used including laser diffraction, scattering methods, or electron microscopy. ${ }^{13-15}$ However these techniques cannot usually resolve more than two similar components, which make them difficult to apply in the case of multi- component mixtures. In such cases NMR is a method of choice for characterisation, since the chemical shift differences or the relaxation properties of different components allows for distinction of the different components of the sample. ${ }^{16,17}$

Proton spin diffusion based experiments are the most widely used NMR methods for determination of the macroscopic structure of complex systems. ${ }^{18,19}$ Notably, methods based on the diffusion of paramagnetic relaxation enhancements (PRE) can be used to determine structures in multi-component systems. ${ }^{20}$ In particular it has been shown that by selective doping of one of the domains of the diamagnetic system with paramagnetic species, and following the PRE, domain sizes can be determined. ${ }^{21}$ It has recently been shown that monitoring spin diffusion of DNP enhanced polarization from a radical 
containing component into a radical free domain, dubbed relayed DNP, can be used to determine domain sizes and architectures in complex multi-component systems. ${ }^{22}$ In these methods, selective doping of one of the domains in the sample is performed in order to introduce spatial heterogeneity in relaxation. This leads to an initial out of equilibrium polarization state, from which relaxation towards equilibrium is monitored. The return to equilibrium can be interpreted using numerical simulations to quantify domain sizes.

Here, we show that the relayed DNP approach, combined with numerical simulations of spin diffusion dynamics, can be used to determine the layer structure of CNPs and estimate the PEG layer thickness.

\section{Experimental}

\section{Molecular structures.}

The molecular structures of compound P and the DSPE-PEG surfactant are shown in Figure 1. (a)

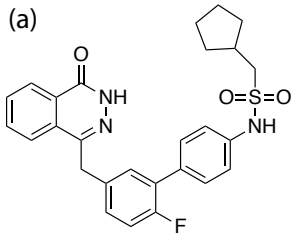

(b)

$$
\text { 16 }
$$

Figure 1. (a) Molecular structure of the compound P. (b) Molecular structure of the DSPE-PEG molecule. $n$ is equal to 113.

\section{CNP Suspension}

A microsuspension of compound P, $12.9 \%(\mathrm{w} / \mathrm{v})$ in $2.6 \%$ (w/v) DSPEPEG5000 (Corden Pharma International, Plankstadt, Germany) in $\mathrm{D}_{2} \mathrm{O}$ was prepared by stirring and repeated sonication in an ultrasonication bath. The microsuspension was then milled for 4 × $30 \mathrm{~min}$, with 15 min intermediate pauses, at $700 \mathrm{rpm}$ using a Fritsch Planetary Micromill P7 (Idar-Oberstein, Germany), equipped with $3.6 \mathrm{~mL}$ zirconium oxide milling vessels and $0.6-0.8 \mathrm{~mm}$ milling beads of zirconium oxide. The milled suspension was collected and the beads were rinsed with $\mathrm{D}_{2} \mathrm{O}$. The nanosuspension was then pelletized at $13680 \mathrm{~g}$ for $20 \mathrm{~min}$ (Hettich Mikro 200 centrifuge from Andreas Hettich $\mathrm{GmbH} \& \mathrm{Co} . \mathrm{KG}$, Tuttlingen, Germany) and washed with $\mathrm{D}_{2} \mathrm{O}$ five times to minimize the free stabilizer concentration.

As the sample is prepared, a fraction of the DSPE-PEG remains free in the $\mathrm{D}_{2} \mathrm{O}$ solution. The free-to-bound ratio was determined by centrifugation and UPLC analysis, and the particle size distribution was measured by laser diffraction. From these data, the surface area per DSPE-PEG and, subsequently, the layer thickness could be estimated. ${ }^{23}$ The tentative structure of the particles is shown in Figure 2.

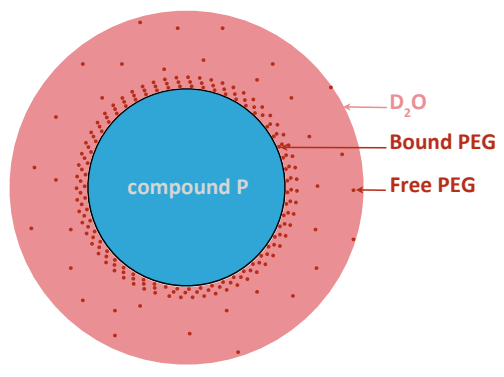

Figure 2. Scheme of the expected structure of the CNP dispersions. The core of the nanoparticle is composed of the crystalline compound P. DSPE-PEG molecules are bound to the surface of the crystalline core, forming a layer. $80 \%$ of the DSPE-PEG is bound to the surface of the CNP and $20 \%$ remains free in the $\mathrm{D}_{2} \mathrm{O}$ solution. $\mathrm{D}_{2} \mathrm{O}$ might partially penetrate the $\mathrm{PEG}$ layer.

DNP solid-state NMR experiments were performed on frozen CNP dispersions.

\section{DNP Samples and experiments}

About $30 \mathrm{mg}$ of $99.95 \%{ }^{12} \mathrm{C}$ enriched glycerol- $d_{8}$ was transferred to an Eppendorf vial and weighed $(\rho=\mathrm{g} / \mathrm{ml})$. A vial of CNP- $\mathrm{D}_{2} \mathrm{O}$ dispersion was stirred for 2 hours at room temperature, and sonicated for 1 minute in an ultrasonic bath before use. The required amount of the CNP- $\mathrm{D}_{2} \mathrm{O}$ dispersion was added to the glycerol vial to obtain a $30 \%{ }^{12} \mathrm{C}$-glycerol$d_{8} / 70 \% \mathrm{CNP}-\mathrm{D}_{2} \mathrm{O}$ dispersion by volume. The required amount of $\mathrm{H}_{2} \mathrm{O}$ was added to the vial to obtain a $30 \%{ }^{12} \mathrm{C}$-glycerol$d_{8} / 60 \% \mathrm{CNP}-\mathrm{D}_{2} \mathrm{O} / 10 \% \mathrm{H}_{2} \mathrm{O}$ solution by volume. A few milligrams of the biradical polarizing agent $\mathrm{AMUPol}^{24}$ was weighed out into a third Eppendorf vial to afford a concentration of 10-12 mM. All of the AMUPol was observed to completely and rapidly dissolve in the CNP- $\mathrm{D}_{2} \mathrm{O}-\mathrm{H}_{2} \mathrm{O}$-glycerol dispersions. Finally, a small amount (typically $0.5 \mathrm{mg}$ ) of ${ }^{13} \mathrm{C}$ labelled sodium formate was weighed out into an Eppendorf vial, and the CNP- $\mathrm{D}_{2} \mathrm{O}-\mathrm{H}_{2} \mathrm{O}-{ }^{12} \mathrm{C}$-glycerol- $d_{8}$-AMUPol dispersion was then transferred into the vial and stirred to dissolve the sodium formate.

For DNP experiments, typically 20-25 $\mu \mathrm{L}$ of the AMUPol/CNP- $\mathrm{D}_{2} \mathrm{O} / \mathrm{H}_{2} \mathrm{O} /{ }^{12} \mathrm{C}$-glycerol- $d_{8} /{ }^{13} \mathrm{C}$-formate dispersion was transferred with a micro-pipette into a $3.2 \mathrm{~mm}$ sapphire DNP rotor. The rotors were capped with a silicone plug and a zirconia drive cap. The filled DNP rotor was then inserted into the pre-cooled (ca. $100 \mathrm{~K}$ ) $3.2 \mathrm{~mm}$ MAS DNP NMR probe where the solution was rapidly frozen within several seconds.

DNP experiments were performed on a $263 \mathrm{GHz} / 400 \mathrm{MHz}$ Avance III Bruker DNP solid-state NMR spectrometer. The spectrometer is equipped with a LTMAS $3.2 \mathrm{~mm}$ triple resonance probe and a $263 \mathrm{GHz}$ gyrotron capable of outputting ca. 5-10 W of CW microwaves. The probe was configured into ${ }^{1} \mathrm{H} /{ }^{13} \mathrm{C} /{ }^{15} \mathrm{~N}$ triple resonance HXY mode. The sweep coil of the main magnetic field was optimized so that the microwave irradiation gave the maximum positive proton DNP enhancement with AMUPol. DNP enhancements were determined by comparing the peaks areas of the spectra acquired with and without microwave irradiation. Variable amplitude cross-polarization was used to transfer polarization from ${ }^{1} \mathrm{H}$ to ${ }^{13} \mathrm{C}$. SPINAL-64 heteronuclear ${ }^{1} \mathrm{H}$ decoupling with rf fields of 100 $\mathrm{kHz}$ was applied in all cases.

\section{Numerical Simulations.}

Numerical simulations were performed using the Matlab differential equation solver "pdepe", which solves initial-boundary condition problems for partial differential equations in space $(x)$ and time $(t)$ domains. As described in detail in reference 22 , two different differential equations were used for the cases where the microwave irradiation ( $\mu$ wave) is on or off. Initial and boundary conditions do not change between the $\mu$ wave on and off cases, whereas the local equilibrium polarization $P_{0}$ changes between $\mu$ waves on and $\mu$ waves off 
cases. The values of $T_{1}$ or $T_{\mathrm{B}}$ and $P_{0}$ where defined using a hyperbolic secant function that depends on space. For both $\mu$ waves on and off cases, numerical values of the polarization function that satisfy the differential equations were found, and the polarization was scaled by $|J(\mathrm{x})|$, where $|J(\mathrm{x})|$ is the Jacobian. The simulated signal was obtained by integration of the resulting polarization using a trapezoidal numerical integration. The simulated enhancement was calculated as the ratio of the integrated $\mu$ waves on and off signals. The normalization factors for the signals were obtained using the value of the fitted signal at steady state.

\section{Results and Discussion}

\section{Relaxation Times}

${ }^{1} \mathrm{H}$ saturation recovery experiments were performed in order to determine the longitudinal relaxation times $T_{1}$ of both pure dry compound $P$ and pure dry DSPE-PEG molecules. In a saturation recovery sequence, the ${ }^{1} \mathrm{H}$ magnetization is first saturated, then allowed to recover to equilibrium polarization. The time constant of the (exponential) recovery of the polarization in a dry solid sample exempt of any radical is labelled $T_{1} .{ }^{1} \mathrm{H}$ longitudinal relaxation time measurements were performed on the pure solids and gave $T_{1, \mathrm{P}}=37 \mathrm{~s}$ and $T_{1, \mathrm{DSPE}-\mathrm{PEG}}=6.8 \mathrm{~s}$. This measurement is important in order to be able to estimate how strong the inherent relaxation in the two domains are, vide infra.

\section{DNP enhanced solid-sate NMR.}

In our approach, the sample was doped with a paramagnetic polarization source following the procedure described in the sample preparation section above. ${ }^{1} \mathrm{H}$ recovery rates were then measured using carbon detected ${ }^{1} \mathrm{H}-{ }^{13} \mathrm{C}$ CPMAS saturation recovery experiments. A ${ }^{1} \mathrm{H}-{ }^{13} \mathrm{C}$ CPMAS saturation recovery sequence is shown in Figure 3. In these experiments the buildup of the ${ }^{13} \mathrm{C}$ resonances in the spectrum as function of $\tau$ corresponds to the recovery of ${ }^{1} \mathrm{H}$ magnetization close to the corresponding carbon. If the different spatial components of the sample have resolvable carbon signals, this allows us to follow the magnetization recovery in the corresponding domains within the formulation. In the present case we observe resolvable ${ }^{13} \mathrm{C}$ signals for the labelled sodium formate in the radical solution, for the PEG in the surface layer, and for compound $\mathrm{P}$ in the nanocrystals.

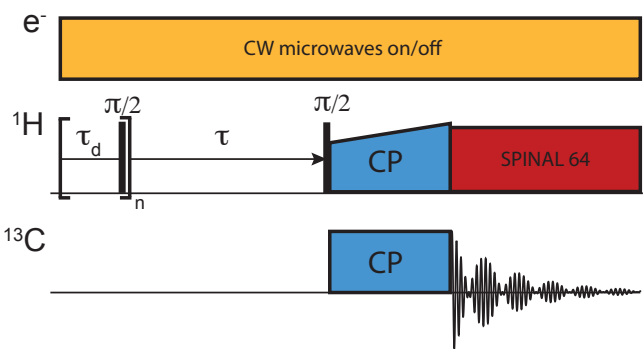

Figure 3. ${ }^{1} \mathrm{H}-{ }^{13} \mathrm{C}$ saturation recovery pulse sequence used for acquisition of spectra. $\tau_{\mathrm{d}}$ is the saturation delay and was set to 20 ms. The number of saturation loops was 20. $\tau$ is the polarization delay.

All the ${ }^{13} \mathrm{C}$ resonances in the spectra of the formulations were assigned to the different components, as shown in Figure 4, using reference spectra of the pure dry solids at the same temperature and spinning rates.
${ }^{13} \mathrm{C}$ CPMAS spectra of frozen CNP dispersions acquired with (red spectra) and without (black spectra) DNP for signal build-up and signal enhancement are shown in Figure 4. Since the solution was fully ${ }^{13} \mathrm{C}$-depleted, $1 \mathrm{mg}$ of ${ }^{13} \mathrm{C}$-sodium formate (called formate from now on) was added to the solution in order to be able to follow the behavior of the radical containing solution through ${ }^{13} \mathrm{C}$ nuclei. The silicone plug used to cap the rotors gives a large signal around $-2.3 \mathrm{ppm}$ in the ${ }^{13} \mathrm{C}$ NMR spectrum.

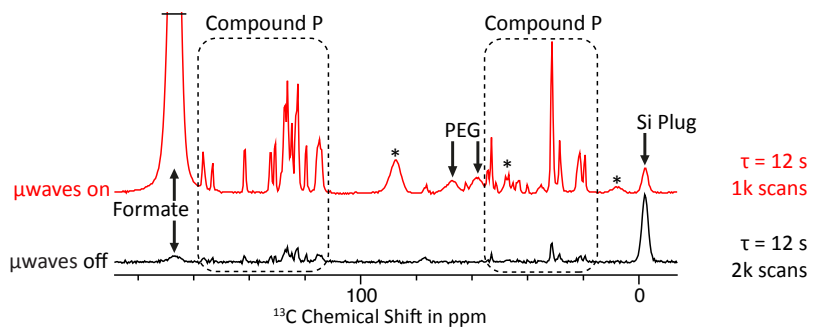

Figure 4. DNP enhanced ${ }^{13} \mathrm{C}$ CPMAS solid-state NMR spectrum of frozen CNP dispersion in ${ }^{12} \mathrm{C}$-glycerol- $d_{8} / \mathrm{D}_{2} \mathrm{O} / \mathrm{H}_{2} \mathrm{O}(60 / 30 / 10$ $\mathrm{v} / \mathrm{v} / \mathrm{v}$ ) containing $0.5 \mathrm{mg}$ of sodium formate and $12 \mathrm{mM}$ AMUPol, with (red) and without (black) microwave irradiation obtained at $100 \mathrm{~K}, 8 \mathrm{kHz}$ MAS, and $\mathrm{B}_{0}=9.4 \mathrm{~T}$. The number of scans and polarization delay are shown on the right side of the spectra. Stars indicate spinning sidebands.

Both build-up time and enhancement as a function of the polarization delay were measured for compound $\mathrm{P}$, formate, and DSPE-PEG resonances as shown in Figure 5.

In Figure 5e, the formate build-up time is seen to be monoexponential, independent of the microwave irradiation, and with a time constant around $1.2 \mathrm{~s}$, which is expected for a homogeneous radical containing solution. ${ }^{25}$ As a consequence, we see in Figure $5 \mathrm{f}$ that the formate enhancement is constant as a function of the polarization delay. This observation confirms that formate is restricted to the solution outside the CNPs, and that the radical is homogeneously dispersed in this domain, in agreement with literature. ${ }^{22}$ In Figure 5c, longer build-up times for the compound $\mathrm{P}$ (both with and without $\mu$ waves) than for the formate are measured. This observation suggests that the compound $\mathrm{P}$ domain is, as expected, not doped with the radical molecules. The build-up time of the compound $\mathrm{P}$ is shorter than its intrinsic $T_{1, \mathrm{P}}$. This is due to the fact that spin diffusion accelerates the apparent build-up of ${ }^{1} \mathrm{H}$ spins inside the compound $\mathrm{P}$ domain. ${ }^{22,26-28}$ Also, we notice that the compound $\mathrm{P}$ resonance build-up time is slightly smaller in the off than in the on case. This is also a signature of a domain being polarized by spin diffusion. ${ }^{22,26-28}$ As a consequence we measure an increase of the DNP enhancement of compound $\mathrm{P}$ as a function of the polarization delay is measured, as shown in Figure 5d (this is the first example of the observation of such a monotonic increase in enhancement). 
(a)

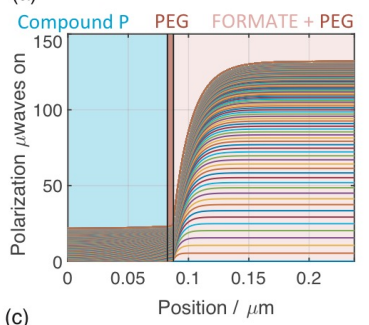

(b)
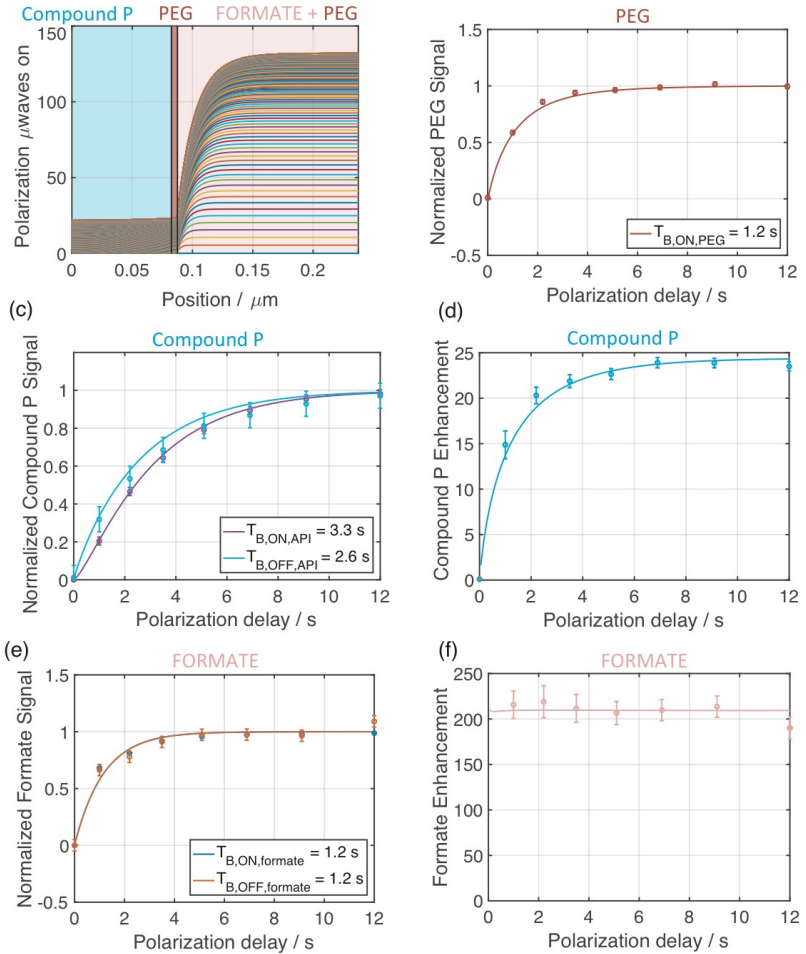

(d)
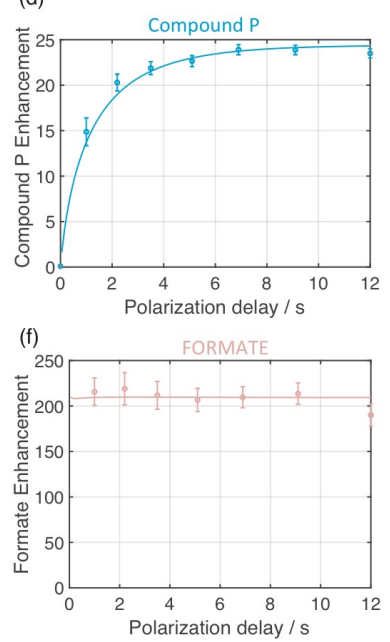

Figure 5. (a) Simulated polarization as a function of position for different time steps. (b) Normalized signal from the ${ }^{13} \mathrm{C}$ DSPEPEG resonance with microwaves as a function of the polarization delay. (c) Normalized signal from the ${ }^{13} \mathrm{C}$ compound $\mathrm{P}$ resonances with (purple) and without (blue) microwaves as a function of the polarization delay. (d) Compound $\mathrm{P}$ enhancement as a function of the polarization delay. (e) Normalized signal from the ${ }^{13} \mathrm{C}$ formate resonances with (blue) and without (orange) microwaves as a function of the polarization delay. In figures (b) to (f), circles represent experimental data. The errors on the signals and enhancements were calculated using the signal to noise ratio of both $\mu$ waves on and off spectra as a standard deviation. Solid lines represent numerical simulations with the parameter given in the manuscript and SI.

The signal to noise ratio of the $\mu$ waves off spectra of the ${ }^{13} \mathrm{C}$ DSPE-PEG resonance was not good enough to extract a proper build-up curve. The $\mu$ waves on DSPE-PEG resonance shows a fast build-up which accounts for the presence of radical molecules in proximity to the DSPE-PEG groups, both at the surface of the nanocrystal and in the solution.

\section{Numerical Simulations}

The transport of DNP enhanced polarization by ${ }^{1} \mathrm{H}$ spin diffusion in the CNP system behaves like thermal or other classical diffusion processes that follows the Fick's $2^{\text {nd }}$ law: ${ }^{29}$

$$
\begin{gathered}
C(x) \cdot \frac{\partial P(x, t)}{\partial t}= \\
\nabla(D(x) \cdot C(x) \cdot P(x, t))-C(x) \cdot \frac{P(x, t)-P_{0}(x)}{T_{1}(x)}
\end{gathered}
$$

where $x$ is the distance from the center of the nanocrystal in $\mu \mathrm{m}, t$ is the time in seconds $(0<t<\infty), P$ is the instantaneous polarization (arbitrary units), $P_{0}$ is the local equilibrium polarization in units of Boltzmann polarization, $D$ is the diffusion coefficient at position $x$ in $\mu \mathrm{m}^{2} \mathrm{~s}^{-1}, T_{1}$ is the longitudinal relaxation time at position $x$ in seconds, $\mathrm{C}$ is the proton concentration at position $x$ in mol. $\mathrm{L}^{-1}$, and $\nabla$ is the Nabla operator which depends on the symmetry of the system. The nanocrystal and the DSPE-PEG layer are proposed here to form a spherical core-shell structure. More details on numerical simulations can be found in ref $^{22}$.

The diameter of compound $\mathrm{P}$ particles was taken to follow a Weibull distribution with a mean diameter of $165 \mathrm{~nm}$ as described in SI, in line with light diffraction measurements, Figure S1. The thickness of the coating layer was taken to be 150 $\mathrm{nm}$ from the particle concentration of $28 \mathrm{nM}$. The local equilibrium polarization is taken to be 1 with and without microwaves for compound P since no DNP is occurring directly in this region. In the surrounding radical solution, the local equilibrium polarization is $\mathrm{P}_{0, \mathrm{ON}}=\varepsilon_{0} \cdot \varepsilon_{\text {depo }}=220 \cdot 0.6=132$ with microwaves corresponding to the experimentally measured enhancement (Figure 5f) and $\varepsilon_{\text {depo }}=0.6$ in line with values found in the literature. ${ }^{30}$ Without microwaves, the equilibrium polarization is taken to be $\mathrm{P}_{0, \mathrm{OFF}}=\varepsilon_{\text {depo }}=0.6$. The proton concentration is taken to be $\mathrm{C}_{\mathrm{P}}=74 \mathrm{M}$ for compound $\mathrm{P}, \mathrm{C}_{\mathrm{DSPE}-\mathrm{PEG}}$ $=101 \mathrm{M}$ for the DSPE-PEG layer, and $\mathrm{C}_{\mathrm{RS}}=11 \mathrm{M}$ in the radical solution, all calculated according to their respective molar mass, density, and number of proton spins per molecule. The reference spin diffusion coefficient value used here

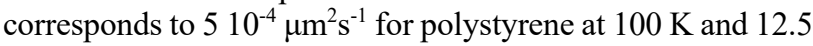
$\mathrm{kHz}$ MAS $(\mathrm{C}=70 \mathrm{M})$. D is then scaled for the corresponding proton concentration in line with literature ${ }^{31}$ for the different regions of the CNP system: $\mathrm{D}_{\mathrm{P}}=7.510^{-4} \mu^{2} \mathrm{~s}^{-1}$, $\mathrm{D}_{\text {DSPE-PEG }}=$ $8.310^{-4} \mu \mathrm{m}^{2} \mathrm{~s}^{-1}$ and $\mathrm{D}_{\mathrm{RS}}=4.010^{-4} \mu \mathrm{m}^{2} \mathrm{~s}^{-1}$ in the radical solution. The experimental values for the intrinsic $T_{1}$ was measured to be $26 \mathrm{~s}$ inside compound $\mathrm{P}$ and $1.2 \mathrm{~s}$ in the surrounding radical solution, in line with experimental measurements (Figure 5e).

Figure $5 \mathrm{~b}-\mathrm{f}$ show the comparison between experiment and prediction from numerical simulations for a spherical nanocrystal having a mean diameter of $165 \mathrm{~nm}$, with a DSPE-PEG layer of $5 \mathrm{~nm}$. In Figure 5e and 5f, numerical simulations reproduce the behavior of both the formate signals and enhancements as a function of time. We confirm here with numerical simulations that the formate is restricted outside the CNPs. In Figure $5 \mathrm{c}$, numerical simulations reproduce the fast build-up times of compound $\mathrm{P}$ compared to its intrinsic $T_{1}$ value $\left(T_{1}=\right.$ $37 \mathrm{~s}$ whereas $T_{\mathrm{B}, \mathrm{ON} / \mathrm{OFF}} \approx 2-3 \mathrm{~s}$ ) which is in agreement with compound $\mathrm{P}$ exempt of radical molecules and polarized from the outside by spin diffusion. In Figure 5d numerical simulations reproduce the increasing enhancement of compound $\mathrm{P}$ with time. This is due to a faster signal build-up without microwave irradiation $\left(T_{\mathrm{B}, \mathrm{OFF}}=2.3 \mathrm{~s}\right)$ than with microwave irradiation $\left(T_{\mathrm{B}, \mathrm{OFF}}=3.2 \mathrm{~s}\right)$, as measured in Figure $5 \mathrm{c}$. Physically, this means that hyperpolarization arrives in compound $\mathrm{P}$ by spin diffusion only after the time needed to go through the DSPE-PEG layer. This explains the delayed increase of the $\mu$ waves on compound P signal in Figure 5c, and the delayed increase of the experimental and simulated enhancements. This is a clear signature of compound $\mathrm{P}$ being located below a surface layer. Finally, numerical simulations also reproduce the fast signal build-up of the DSPE-PEG with microwaves.

The fit between numerical simulations and experimental data, as shown in Figure S2, suggests that the PEG forms a layer between $\mathrm{L}=5$ and $10 \mathrm{~nm}$ thick, with a $T_{1, \mathrm{DSPE}-\mathrm{PEG}}=100-500$ ms. As detailed in the SI, the simulated compound P build-up depends on the size of the PEG layer. 
We notice here that the DSPE-PEG $T_{1}$ is much shorter than expected from experimental measurements $(6.8 \mathrm{~s})$. This suggest that the radical AMUPol has an affinity for the DSPEPEG layer, as previously observed for silica materials by Perras et. $a l^{32}$ and that the "PEG layer" is actually a "PEG + AMUPol layer". We note that a high AMUPol/DSPE-PEG affinity would lead to a significant signal quenching in the DSPE-PEG layer but would affect the spin diffusion process.

Note that that deviations of the particle shape from exactly spherical assumed here do not significantly affect the determination of the thickness of the layer (unless the deviation causes the surface to volume ratio to change substantially).

\section{Conclusions}

We have shown that CNPs can be efficiently polarized by DNP relayed by ${ }^{1} \mathrm{H}$ spin diffusion. By performing only two saturation recovery experiments, we can measure the time dependence of signals and enhancements which are characteristic of the spatial arrangement and relaxation properties of each of the components of the system. We model the transport of polarization with numerical simulations, and determine by comparing numerical simulations and experimental data the thickness of the PEG layer in CNPs of compound P is between 5 and $10 \mathrm{~nm}$.

\section{Acknowledgments}

Financial support from AstraZeneca is acknowledged for this work. We would like to thank Lennart Lindfors (AstraZeneza) for useful discussions.

\section{References}

(1) Pouton, C. W. Lipid formulations for oral administration of drugs: non-emulsifying, self-emulsifying and 'selfmicroemulsifying' drug delivery systems Eur. J. Pharm. Sci. 2000, 11, S93-S98.

(2) Jouyban, A. Review of the cosolvency models for predicting solubility of drugs in water-cosolvent mixtures J. Pharm. Pharm. Sci. 2008, 11, 32-57.

(3) Loftsson, T.; Brewster, M. E. Cyclodextrins as functional excipients: Methods to enhance complexation efficiency $J$. Pharm. Sci. 2012, 101, 3019-3032.

(4) Jinno, J.; Kamada, N.; Miyake, M.; Yamada, K.; Mukai, T.; Odomi, M.; Toguchi, H.; Liversidge, G. G.; Higaki, K.; Kimura, T. Effect of particle size reduction on dissolution and oral absorption of a poorly water-soluble drug, cilostazol, in beagle dogs Journal of Controlled Release 2006, 111, 56-64.

(5) Ganta, S.; Paxton, J. W.; Baguley, B. C.; Garg, S. Formulation and pharmacokinetic evaluation of an asulacrine nanocrystalline suspension for intravenous delivery International Journal of Pharmaceutics 2009, 367, 179-186.

(6) Sigfridsson, K.; Skantze, P.; Skantze, U.; Svensson, L.; Lofgren, L.; Nordell, P.; Michaelsson, E.; Smedsrod, B.; Fuglesteg, B.; Elvevold, K.; Lindfors, L. Nanocrystal formulations of a poorly soluble drug. 2. Evaluation of nanocrystal liver uptake and distribution after intravenous administration to mice International Journal of Pharmaceutics 2017, 524, 248-256.

(7) Sigfridsson, K.; Skantze, U.; Skantze, P.; Johansson, S.; Grant, I.; Smedsrod, B.; Fuglesteg, B.; Elvevold, K.; Lindfors, L. Nanocrystal formulations of a poorly soluble drug. 1. In vitro characterization of stability, stabilizer adsorption and uptake in liver cells International Journal of Pharmaceutics 2017, 518, 2940.

(8) Immordino, M. L.; Dosio, F.; Cattel, L. Stealth liposomes: review of the basic science, rationale, and clinical applications, existing and potential International Journal of Nanomedicine 2006, 1, 297-315.

(9) Barenholz, Y. Doxil (R) - The first FDA-approved nano-drug: Lessons learned Journal of Controlled Release 2012, 160, 117134.

(10) Ito, A.; Konnerth, C.; Schmidt, J.; Peukert, W. Effect of polymer species and concentration on the production of mefenamic acid nanoparticles by media milling European Journal of Pharmaceutics and Biopharmaceutics 2016, 98, 98107.

(11) Zhang, H.; Hu, H. X.; Zhang, H. R.; Dai, W. B.; Wang, X. L.; Wang, X. Q.; Zhang, Q. Effects of PEGylated paclitaxel nanocrystals on breast cancer and its lung metastasis Nanoscale 2015, 7, 10790-10800.

(12) Rabanel, J. M.; Hildgen, P.; Banquy, X. Assessment of PEG on polymeric particles surface, a key step in drug carrier translation Journal of Controlled Release 2014, 185, 71-87.

(13) Wilson, J. D.; Bechtel, D. B.; Todd, T. C.; Seib, P. A. Measurement of wheat starch granule size distribution using image analysis and laser diffraction technology Cereal Chemistry 2006, 83, 259-268.

(14) Hendrich, C.; Favre, L.; Ievlev, D. N.; Dobrynin, A. N.; Bras, W.; Hormann, U.; Piscopiello, E.; Van Tendeloo, G.; Lievens, P.; Temst, K. Measurement of the size of embedded metal clusters by mass spectrometry, transmission electron microscopy, and small-angle X-ray scattering Appl. Phys. A-Mater. Sci. Process. 2007, 86, 533-538.

(15) Amaral, S. S.; de Carvalho, J. A.; Costa, M. A. M.; Pinheiro, C. An Overview of Particulate Matter Measurement Instruments Atmosphere 2015, 6, 1327-1345.

(16) Telkki, V. V.; Lounila, J.; Jokisaari, J. Determination of pore sizes and volumes of porous materials by Xe-129 NMR of xenon gas dissolved in a medium Journal of Physical Chemistry B 2005, 109, 24343-24351.

(17) Chemmi, H.; Petit, D.; Levitz, P.; Denoyel, R.; Galarneau, A.; Korb, J. P. Noninvasive Experimental Evidence of the Linear Pore Size Dependence of Water Diffusion in Nanoconfinement Journal of Physical Chemistry Letters 2016, 7, 393-398.

(18) Clauss, J.; Schmidt-Rohr, K.; Spiess, H. W. DETERMINATION OF DOMAIN SIZES IN HETEROGENEOUS POLYMERS BY SOLID-STATE NMR Acta Polymerica 1993, 44, 1-17.

(19) Demco, D. E.; Johansson, A.; Tegenfeldt, J. PROTON SPIN-DIFFUSION FOR SPATIAL HETEROGENEITY AND MORPHOLOGY INVESTIGATIONS OF POLYMERS Solid State Nuclear Magnetic Resonance 1995, 4, 13-38.

(20) Bertini, I.; Luchinat, C.; Parigi, G.; Ravera, E. NMR of Paramagnetic Molecules: Applications to Metallobiomolecules and Models; Elsevier Science, 2016.

(21) Schlagnitweit, J.; Tang, M. X.; Baias, M.; Richardson, S.; Schantz, S.; Emsley, L. Nanostructure of Materials Determined by Relayed Paramagnetic Relaxation Enhancement Journal of the American Chemical Society 2015, 137, 12482-12485.

(22) Pinon, A. C.; Schlagnitweit, J.; Berruyer, P.; Rossini, A. J.; Lelli, M.; Socie, E.; Tang, M. X.; Pham, T.; Lesage, A.; Schantz, S.; Emsley, L. Measuring Nano- to Microstructures from Relayed Dynamic Nuclear Polarization NMR Journal of Physical Chemistry C 2017, 121, 15993-16005.

(23) Perry, J. L.; Reuter, K. G.; Kai, M. P.; Herlihy, K. P.; Jones, S. W.; Luft, J. C.; Napier, M.; Bear, J. E.; DeSimone, J. M. PEGylated PRINT Nanoparticles: The Impact of PEG Density on Protein Binding, Macrophage Association, Biodistribution, and Pharmacokinetics Nano Letters 2012, 12, 5304-5310. 
(24) Sauvee, C.; Rosay, M.; Casano, G.; Aussenac, F.; Weber, R. T.; Ouari, O.; Tordo, P. Highly Efficient, Water-Soluble Polarizing Agents for Dynamic Nuclear Polarization at High Frequency Angewandte Chemie-International Edition 2013, 52, 10858-10861.

(25) Zagdoun, A.; Casano, G.; Ouari, O.; Schwarzwalder, M.; Rossini, A. J.; Aussenac, F.; Yulikov, M.; Jeschke, G.; Coperet, C.; Lesage, A.; Tordo, P.; Emsley, L. Large Molecular Weight Nitroxide Biradicals Providing Efficient Dynamic Nuclear Polarization at Temperatures up to $200 \mathrm{~K}$ Journal of the American Chemical Society 2013, 135, 12790-12797.

(26) Rossini, A. J.; Zagdoun, A.; Hegner, F.; Schwarzwalder, M.; Gajan, D.; Coperet, C.; Lesage, A.; Emsley, L. Dynamic Nuclear Polarization NMR Spectroscopy of Microcrystalline Solids Journal of the American Chemical Society 2012, 134, 1689916908.

(27) Rossini, A. J.; Widdifield, C. M.; Zagdoun, A.; Lelli, M.; Schwarzwalder, M.; Coperet, C.; Lesage, A.; Emsley, L. Dynamic Nuclear Polarization Enhanced NMR Spectroscopy for Pharmaceutical Formulations Journal of the American Chemical Society 2014, 136, 2324-2334.

(28) van der Wel, P. C. A.; Hu, K. N.; Lewandowski, J.; Griffin, R. G. Dynamic nuclear polarization of amyloidogenic peptide nanocrystals: GNNQQNY, a core segment of the yeast prion protein Sup35p Journal of the American Chemical Society 2006, 128, 10840-10846.

(29) Fick, A. Ueber diffusion; J.A. Barth, 1855.

(30) Mentink-Vigier, F.; Paul, S.; Lee, D.; Feintuch, A.; Hediger, S.; Vega, S.; De Paepe, G. Nuclear depolarization and absolute sensitivity in magic-angle spinning cross effect dynamic nuclear polarization Physical Chemistry Chemical Physics 2015, 17, 21824-21836.

(31) Wenckebach, W. T. Essentials of Dynamic Nuclear Polarization; Spindrift Publications, 2016.

(32) Perras, F. A.; Wang, L. L.; Manzano, J. S.; Chaudhari, U.; Opembre, N. N.; Johnson, D. D.; Slowing, I.; Pruski, M. Optimal sample formulations for DNP SENS: The importance of radicalsurface interactions Current Opinion in Colloid \& Interface Science 2018, 33, 9-18. 